\title{
Protein Arginine Methylation of Npl3 Promotes Splicing of the SUS1 Intron harboring Non-consensus 5' Splice Site and Branch Site
}

Bhavana Muddukrishna ${ }^{*}$, Christopher A. Jackson ${ }^{*}$, and Michael C. Yu ${ }^{\#}$

Department of Biological Sciences, State University of New York at Buffalo, Buffalo,

New York, United States of America

Running title: protein arginine methylation and pre-mRNA splicing

*: B.M. and C.A.J. contributed equally to this work.

\#: Address correspondence to Michael C. Yu, mcyu@buffalo.edu

Department of Biological Sciences

State University of New York at Buffalo

109 Cooke Hall

Buffalo, NY. 14260

Tel: 716-645-4931

Fax: 716-645-2975

E-mail: mcyu@buffalo.edu

Keywords: protein arginine methylation; pre-mRNA splicing; U1 snRNP; Hmt1; Npl3 
Muddukrishna

\section{$\underline{\text { Abstract }}$}

Protein arginine methylation occurs on spliceosomal components and spliceosome-associated proteins, but how this modification contributes to their function in pre-mRNA splicing remains sparse. Here we provide evidence that protein arginine methylation of the yeast SR-/hnRNP-like protein Npl3 plays a role in facilitating efficient splicing of the SUS1 intron that harbors a non-consensus 5' splice site and branch site. In yeast cells lacking the major protein arginine methyltransferase HMT1, we observed a change in the co-transcriptional recruitment of the U1 snRNP subunit Snp1 and Np13 to pre-mRNAs harboring both consensus (ECM33 and ASC1) and non-consensus (SUS1) 5' splice site and branch site. Using an Npl3 mutant that phenocopies wild-type Npl3 when expressed in $\Delta h m t 1$ cells, we showed that the arginine methylation of $\mathrm{Npl} 3$ is responsible for this. Examination of pre-mRNA splicing efficiency in these mutants reveals the requirement of Npl3 methylation for the efficient splicing of SUS1 intron 1, but not of ECM33 or ASC1. Changing the 5' splice site and branch site in SUS1 intron 1 to the consensus form restored splicing efficiency in an Hmt1-independent manner. Results from biochemical studies show that methylation of Npl3 promotes its optimal association with the U1 snRNP through its association with the U1 snRNP subunit Mud1. Based on these data, we propose a model in which $\mathrm{Hmt} 1$, via arginine methylation of $\mathrm{Npl3}$, facilitates U1 snRNP engagement with the pre-mRNA to promote usage of nonconsensus splice sites by the splicing machinery. 


\section{Introduction}

Eukaryotic gene expression requires functional integration of splicing and transcription of precursor mRNAs (pre-mRNAs) [reviewed in 1,2]. During pre-mRNA splicing, it is critical that introns are precisely removed from the precursor transcript via the spliceosome, a macromolecular RNA-protein complex whose recruitment and activities are controlled by cis sequence elements and by trans-acting factors [reviewed in 3, 4]. In Saccharomyces cerevisiae, five small nuclear ribonucleoproteins (snRNPs) comprise the core of the spliceosome. In the consensus model of spliceosome assembly, the U1 snRNP first recognizes the 5' splice site in the pre-mRNA through base-pairing between the 5'-end of the U1 snRNA and the 5' splice site sequence, forming the earliest commitment complex (CC1) [5-7]. The branch site is then recognized by the branchpoint binding protein (BBP/Ms15) and its binding partner Mud2 to form commitment complex 2 (CC2) [8-10]. The BBP-Mud2 heterodimer then interacts with the U1 snRNP, forming a bridge between the 5' splice site and the branch site [11]. Prp5 and Sub2, both of which are DEAD/DECD box proteins, then promote displacement of BBP and Mud2 by the U2 snRNP at the branch site in an ATP-dependent manner, resulting in the pre-spliceosome or A complex [12-14]. The preformed U4/U6.U5 tri-snRNP then joins to form the assembled spliceosome [15-18]. Following the binding of the tri-snRNP, major structural rearrangements occur within the spliceosome, resulting in the release of $\mathrm{U} 1$ and $\mathrm{U} 4$ snRNPs and formation of new base-pairings between U6 and the 5' splice site and between U2 and U6 snRNA [19, 20]. A protein complex called the nineteen complex (NTC) then stabilizes the association of U5 and U6 with the spliceosome, thereby allowing the formation of an activated spliceosome to catalyze the actual splicing 
reaction [21]. The snRNPs and non-snRNP-associated factors are co-transcriptionally recruited through an ordered process [22-24]. Although splicing can occur posttranscriptionally, the coupling of this process to transcription likely maximizes its fidelity and efficiency [25].

While the basic components of the splicing machinery are conserved between $S$. cerevisiae and mammals, splicing regulators of the serine/arginine-rich (SR) protein family are present only in the latter [26]. Previous studies in mammalian cells showed that SR proteins stabilize interactions between the U1 snRNP and pre-mRNAs [reviewed in 27, 28]. It is thought that SR proteins bind to the exonic sequences adjacent to suboptimal splice sites, consequently promoting the recruitment of U1 and U2 snRNPs and thereby playing a significant role in constitutive splicing of pre-mRNAs as well as regulating alternative splicing. In yeast, most splice sites obey a strict consensus, and since only a handful of intron-containing genes possess more than a single intron it was thought that the lack of SR proteins in the budding yeast reflects lack of a need for alternative splicing [29]. Nevertheless, a number of yeast proteins such as Npl3, Hrb1, and Gbp2 possess characteristics of mammalian SR proteins [30]. Interestingly, Npl3 additionally shares characteristics with heterogeneous nuclear ribonucleoproteins (hnRNPs) - a large number of RGG boxes and RNA-recognition motifs (RRMs) [reviewed in 31, 32].

Several post-translational modifications have been implicated in the control of pre-mRNA splicing [reviewed in 33]. For example, ubiquitination of the DExD/H box family protein Brr2 suppresses its ability to unwind U4/U6 RNA duplex [34]. Recently, protein arginine methylation has been linked to the control of pre-mRNA splicing in 
Muddukrishna

several model systems: budding yeast [35], cultured mammalian cells [36, 37], plants [38], and mice [39]. Protein arginine methylation alters the biochemical properties of the side chain of the amino acid arginine [reviewed in 40]. This modification is catalyzed by members of the protein arginine methyltransferase (PRMT) family of enzymes, which are divided into four subtypes based on the specific type of methylarginine that is formed. The type I PRMTs transfer either one or two methyl groups from S-adenosyl- $L$ methionine (AdoMet) to a single guanidino nitrogen on a protein-incorporated arginine residue, thus forming monomethylarginine (MMA) or asymmetric dimethylarginine (aDMA), respectively. Type II PRMTs likewise catalyze monomethylation, but then add the second methyl group from AdoMet to the opposing guanidino nitrogen within the arginine residue, thereby forming symmetric dimethylarginine (sDMA). Sm proteins, which are critical to the assembly of functional U snRNPs in the cell, contain sDMAs that are modified by PRMT5, a type II PRMT [41, 42]. In S. cerevisiae, Hmt1 (also termed Rmt1) is the only known type I PRMT and it is the yeast homolog of mammalian PRMT1 $[43,44]$. Hmt1 has been shown to methylate the SR-/hnRNP-like Npl3 $[44,45]$ and the vast majority of aDMAs are present within the RGG context [46].

Previously, we showed that Hmt1 methylates the U1 snRNP subunit Snp1 and that Hmt1 is required for proper co-transcriptional recruitment of specific snRNP subunits and snRNP-associated factors to their genomic targets [35]. In the current study, we demonstrate that Hmt1 plays a role in facilitating the spliceosome usage of nonconsensus splice sites, and that it does so via methylation of the SR-/hnRNP-like protein Npl3. Our data show that $\Delta h m t l$ cells display altered recruitment of U1 snRNP subunit Snp1 and SR-like protein Npl3 to intron-containing genes SUS1, ECM33, and ASC1 in an 
RNA-dependent manner. However, only SUS1 intron 1, which harbors a non-consensus 5' splice site and branch site, exhibits a decreased splicing efficiency in these cells. Using an Npl3 mutant that phenocopies wild-type Npl3 behavior when expressed in $\Delta h m t 1$ cells, we show that the arginine methylation of $\mathrm{Npl} 3$ is responsible for the recruitment and splicing efficiency changes observed in $\Delta h m t l$ cells. Biochemical characterizations using methylated and unmethylated form of Npl3 indicate a methylation-dependent association between Npl3 and the U1 snRNP via Mud1, a subunit of U1 snRNP. Overall, our data support a model in which Hmt1, via methylating Npl3, promotes optimal U1 snRNP engagement with non-consensus 5' splice site and branch site in SUS1 in order to achieve its efficient splicing.

\section{Materials and Methods}

\subsection{Yeast strains used in this study}

All yeast strains used are listed in Table S1. All plasmids used are listed in Table S2. All primers used are listed in Table S3. Cells were grown at $30^{\circ} \mathrm{C}$ on YPD medium ( $1 \%$ yeast extract, $2 \%$ bactopeptone, $2 \%$ glucose, w/v) unless otherwise stated. Genomic deletions and integration of epitope tag cassettes was performed as previously described $[47,48]$

\subsection{Chromatin immunoprecipitation (ChIP)}

ChIPs were performed as described previously [49, 50], except for the sonication condition (Branson Digital Sonifier 450,3mm tapered microtip, 20\% amplitude, $20 \mathrm{sec}$ pulse followed by $55 \mathrm{sec}$ pause for 15 cycles). For each IP, anti-myc (Thermo-Fisher cat\# MS127P), $\alpha$-Rpb3 (Neoclone cat\#W0012) or anti-IgG (Jackson ImmunoResearch cat\# 209-005-082) antibodies were pre-coupled to protein A-sepharose beads. qPCR was 
Muddukrishna

performed on a Bio-Rad MyiQ5 real-time thermal cycler in $20 \mu$ reactions with SsoAdvanced Universal SYBR Green Supermix (Bio-Rad), $2 \mu 1$ of DNA sample (input or IP), and primers at a final concentration of $0.25 \mu \mathrm{M}$ for each primer. Percent of input was calculated using the $\Delta \mathrm{C}_{\mathrm{T}}$ method and statistical testing was performed by Student's ttest. All values reported are the mean of three biological replicates $(n=3)$, with error bars indicating the standard error of the mean. For RNase treatment, sonicated chromatin samples were treated with $400 \mu \mathrm{g}$ of RNase A and 800 units of RNase A/T1 Cocktail (Ambion \#AM2286) prior to IP. IPs and qPCR were performed on RNase treated samples as described above. All the primers used in the real-time PCR experiments are listed in Table S3.

\subsection{Reverse transcription and quantitative real-time PCR analysis (RT-qPCR)}

Overnight yeast cultures were subcultured 1:100 into YEPD and grown to $\mathrm{OD}_{600} \approx 0.35$ 0.45 , whereupon they were harvested and cell pellet flash-frozen in liquid nitrogen. Total RNA was extracted with TRIZOL reagent, followed by treatment with 10U of RNasefree DNase for 30 minutes at $37^{\circ} \mathrm{C}$. The resulting mixture was then further extracted with phenol:chloroform:isoamyl alcohol and resuspended in nuclease-free water. Reverse transcription was performed on $250 \mathrm{ng}$ of RNA with Superscript III (Thermo-Fisher), primed with $0.25 \mu \mathrm{g}$ oligo-dT(12-18) and $0.05 \mu \mathrm{g}$ random hexamer, for 1 hour at $50^{\circ} \mathrm{C}$. The resulting cDNA was treated with $5 \mathrm{U}$ of $\mathrm{RNaseH}$ for 30 minutes at $37^{\circ} \mathrm{C}$ and then heat-inactivated for 20 minutes at $70^{\circ} \mathrm{C}$. qPCR was done as described in section 2.1, using $2 \mu \mathrm{l}$ of cDNA (which equals to approximately $2.5 \mathrm{ng}$ of reverse-transcribed RNA). No-RT controls were performed in parallel. The cDNA and the corresponding No-RT control had at least an $8 \mathrm{C}_{\mathrm{T}}$ difference for all samples. Intron retention percentage was 
Muddukrishna

calculated by the $\Delta \mathrm{C}_{\mathrm{T}}$ method, with intron minus total mRNA, after correcting for primer efficiency. The retention percentage was subtracted from $100 \%$ to obtain the reported values for percentage of intron spliced. Statistical testing was performed using Tukey's HSD test, with the R statistical analysis software. All values reported are the mean of three biological replicates $(n=3)$, with error bars indicating the standard error of the mean.

\subsection{Measurement of SUS1 Mutant Splicing Efficiency}

A SUS1 genomic fragment was amplified from BY4741 genomic DNA, including $226 \mathrm{bp}$ upstream of the ORF and 228 bp downstream, and cloned into pRS415 by PIPE [51].

Site-directed mutagenesis was then performed on this fragment to generate pRS415SUS1[cons], which contains consensus 5' splice site and branch site sequences. pRS415SUS1 and pRS415-SUS1[cons] were transformed into Asus 1 and 4 sus $1 / \Delta h m t 1$ strains. These strains were then grown overnight in SD/Leu ${ }^{-}$media, subcultured 1:100 into $\mathrm{SD} / \mathrm{Leu}^{-}$, and grown to an $\mathrm{OD}_{600} \approx 0.35-0.45$, whereupon they were harvested and flashfrozen in liquid nitrogen. RNA extraction, reverse transcription, and qPCR were performed as described above.

\subsection{Npl3 Protein Pulldown}

$1.5 \mathrm{mg}$ of yeast whole-cell extract in $100 \mu \mathrm{l}$ of storage buffer D (20 mM HEPES-KOH pH 7.8, $50 \mathrm{mM} \mathrm{KCl,} \mathrm{20 \%} \mathrm{Glycerol,} \mathrm{0.2} \mathrm{mM} \mathrm{EDTA,} 1$ mM DTT, 0.5 mM PMSF) was incubated with $5 \mu \mathrm{l}$ of Npl3-sepharose beads (which contains $2.5 \mu \mathrm{g}$ Npl3 protein) for 20 minutes at room temperature. RNase A-treated samples were supplemented with $1 \mathrm{mM}$ $\mathrm{MgCl}_{2}, 20 \mathrm{U}$ of DNase I, and $1 \mu \mathrm{g} / \mathrm{mL}$ of RNase A. After incubation, Npl3-sepharose beads were washed five times with IPP300 (25 mM Tris pH 8.0, $300 \mathrm{mM} \mathrm{NaCl}, 0.1 \%$ NP-40), eluted by boiling in $25 \mu 1$ of $2 \mathrm{X}$ Gel Loading Buffer, and resolved by SDS- 
Muddukrishna

PAGE using a Novex 4-12\% Bis-tris pre-cast gel (Life Technologies). The gel was then fixed, silver stained, and imaged. Additional experimental details are included in the Supplemental Information.

\subsection{Co-immunoprecipitation (coIP)}

Affinity resin for TAP coIPs was generated by covalently linking $500 \mu \mathrm{g}$ of human serum IgG (Sigma cat\#I4506) in PBS + 0.01\% Triton X-100 to $30 \mathrm{mg}$ tosylactivated Dynabeads M-280 (Life Technologies cat $\# 14203$ ) overnight at $37^{\circ} \mathrm{C}$. Beads were then washed and blocked with $1 \mathrm{mg} / \mathrm{ml} \mathrm{BSA}$ in $100 \mathrm{mM}$ Tris $\mathrm{pH} 8.0$ for $4 \mathrm{hrs}$ at room temperature, then washed again and stored in $1 \mathrm{ml}$ of PBS $+0.01 \%$ Triton X-100, 20\% ethanol, and $0.1 \%$ $\mathrm{NaN}_{3}$. Overnight grown yeast cultures were subcultured 1:100 into $50 \mathrm{ml}$ YPD and grown to $\mathrm{OD}_{600} \approx 1.0$, then harvested and washed in PBS with the final cell pellet snapfrozen in liquid nitrogen. Lysates were made by FastPrep (MP Biomedical) in PBSMT (1X PBS, $3 \mathrm{mM} \mathrm{KCl}, 2.5 \mathrm{mM} \mathrm{MgCl} 2,0.5 \%$ Triton X-100) completed with $10 \mu \mathrm{g} / \mathrm{mL}$ RNase A and protease inhibitors ( $1 \mathrm{mM}$ phenylmethylsulfonyl fluoride, $1.3 \mathrm{mM}$ benzamidine, $2.5 \mu \mathrm{g} / \mathrm{ml}$ each of leupeptin, chymostatin, antipain, pepstatin $\mathrm{A}$, and aprotinin). Lysates were normalized to $5 \mathrm{mg} / \mathrm{ml}$ protein concentration by Bradford assay and $5 \mathrm{mg}$ of the lysate was bound to $10 \mu \mathrm{l}$ of pre-washed IgG-Dynabead slurry (300 $\mu \mathrm{g}$ beads) for $2 \mathrm{hrs}$ at $4^{\circ} \mathrm{C}$. Beads were then washed twice with $1 \mathrm{ml}$ IPP300, twice with 1 $\mathrm{ml}$ IPP150 (25 mM Tris pH 8.0, $150 \mathrm{mM} \mathrm{NaCl}, 0.1 \%$ NP-40), eluted in $25 \mu 1$ of $1 \mathrm{X} \mathrm{Gel}$ Loading Buffer, and resolved on a 4-12\% Novex Bis-Tris gel. Following SDS-PAGE, the proteins were transferred to nitrocellulose membrane. The blot was probed with $\alpha$ Np13 antibody and then with $\alpha$-Protein A (Sigma cat\#P3775) antibody.

\subsection{Npl3 Pulldown with U-snRNPs}


$1.5 \mathrm{mg}$ of yeast whole-cell extract prepared as previously described for protein pulldown was incubated with $5 \mu \mathrm{l}$ of Npl3-bound sepharose beads (containing approximately 2.5 $\mu \mathrm{g} \mathrm{Np13} \mathrm{protein)} \mathrm{for} 20$ minutes at room temperature. Beads were then washed five times with ice cold IPP300 and eluted with $200 \mu$ l of RNA Extraction Buffer (50 mM NaOAc pH 5.5, $50 \mathrm{mM} \mathrm{NaCl}, 1 \%$ SDS) and $200 \mu \mathrm{l}$ acid P:C:I (125:24:1

phenol:chloroform:isoamyl alcohol pH 4.5) (Thermo-Fisher cat\#AM9720) for 30 minutes at $37^{\circ} \mathrm{C} .100 \mathrm{ng}$ of control RNA (generated by in vitro transcription from a fragment of the GFP gene) was also added to the elution. Input RNA was extracted by adding $1.5 \mathrm{mg}$ whole cell extract to $200 \mu 1$ RNA Extraction Buffer and $200 \mu$ l acid P:C:I, with $100 \mathrm{ng}$ spike-in control RNA. The RNA was extracted, precipitated, and then DNAse-treated using the DNase Turbo Kit (Thermo-Fisher cat\#AM1907). Reverse transcription was carried out as before with $2.5 \mathrm{ng}$ of RNA as template, and pulldown was quantified as $\%$ of input by $\Delta \Delta \mathrm{C}_{\mathrm{T}}$ using the spike-in RNA control to normalize pulldown.

\subsection{Npl3 pulldown with U1 snRNP subunits}

GST-tagged protein constructs were generated as follows: pGEX-5X-SNP1 was generated by amplifying SNP1 from BY4741 genomic DNA and cloning it between BamHI and NotI sites in pGEX-5X-3. pGEX-4T-MUD2, -LUC7, and -NAM8 were generated by amplification of the respective gene from BY4741 genomic DNA and cloning it between BamHI and XhoI sites in pGEX-4T-1. pGEX-4T-YHC1 and -SNU56 were generated by amplification of the respective gene from BY4741 genomic DNA and cloning it into pGEX-4T-1 by PIPE. pGEX-4T-MUD1 were generated by amplification of the respective gene from BY4741 cDNA and cloning it into pGEX-4T-1 by PIPE. All constructs were confirmed by sequencing prior to transforming into the Rosetta 2 (DE3) 
Muddukrishna

expression strain of E. coli. For each GST-construct, $1 \mathrm{mg}$ of induced and lysed E.coli

cell lysate was bound to $50 \mu \mathrm{l}$ of GSH-magnetic beads (Pierce cat\#88821) for $1 \mathrm{hr}$ at $4{ }^{\circ} \mathrm{C}$. Beads were then washed three times with $1 \mathrm{ml}$ PBS with $1 \mathrm{M} \mathrm{NaCl}, 0.1 \%$ Triton $\mathrm{X}-100$, and $1 \mathrm{mM}$ DTT, followed by two washes with $1 \mathrm{ml}$ PBS with $0.1 \%$ Triton X-100 and 1 mM DTT. $2.5 \mu \mathrm{g}$ Npl3 was then incubated with the GST-coupled GSH-magnetic beads in $1 \mathrm{~mL}$ of PBS with $0.1 \%$ Triton X-100, $1 \mathrm{mM}$ DTT for 30 minutes at room temperature. Beads were then washed four times with $1 \mathrm{ml}$ PBS containing $0.1 \%$ Triton $\mathrm{X}-100,1 \mathrm{mM}$ DTT, and eluted in $25 \mu \mathrm{L} 1 \mathrm{x}$ Gel Loading Buffer. Samples were resolved by the SDSPAGE, transferred to a nitrocellulose membrane, Ponceau stained to check equal loading, and then blotted with $\alpha-\mathrm{Npl3}$. Additional experimental details are included in the Supplemental Information.

\section{Results}

\subsection{Loss of Hmt1 results in reduced in vivo occupancy of intron-containing genes by the U1 snRNP subunit Snp1}

To determine how Hmt1 affects the co-transcriptional recruitment of snRNP subunits and snRNP-associated proteins involved in the early steps of the spliceosome assembly, we measured the in vivo occupancy of intron-containing genes ECM33, SUS1, and $A S C 1$ by Np13, Snp1, Mud2, and the U2 snRNP subunit Lea1 using chromatin immunoprecipitation (ChIP) (Figure 1A and Figure S1A). Both Npl3 [44, 45] and Snp1 [35] are established substrates of Hmt1. ECM33 and ASC1 are examples of typical budding yeast intron-containing genes: they have a single intron with consensus 5' splice site, branch site, and 3'SS (Figure 1B). However, ECM33 has a much shorter first exon 
Muddukrishna

in comparison with $A S C 1$ (58 bp vs. $537 \mathrm{bp).} \mathrm{SUS1} \mathrm{is} \mathrm{one} \mathrm{of} \mathrm{only} 10$ intron-containing genes with more than one intron in the budding yeast and SUS1 contains a non-consensus 5' splice site and branch site at its first intron but retains the consensus sequences for its 5' splice site, branch site, and the 3' splice site at its second intron (Figure 1B).

Interestingly, only about $50 \%$ of two-intron genes in the budding yeast contain nonconsensus branch region sequences versus that of just $7.5 \%$ for single intron genes [52].

Yeast strains of the $H M T l$ and $\Delta h m t l$ backgrounds were engineered to express Cterminal myc-tagged version of the protein. In $\Delta h m t 1$ cells, occupancy by Npl3 was significantly higher across all three intron-containing genes (Figure 2A and Figure S1B; compare Hmt1 "+” bars to Hmt1 "_“ bars above myc IP). Previously, we had observed an increase in the biochemical association between Npl3 and Snp1 in $\Delta h m t 1$ cells [35]. As such, we anticipated seeing a higher level of gene occupancy by Snp1 in cells that lack Hmt1. However, the converse was true; Snp1 occupancy was significantly lower across all genes tested in $\Delta h m t 1$ cells (Figure 2B and Figure S1C; compare Hmt1 "+" bars to Hmt1 “_“ bars above myc IP), approaching near background levels.

We next examined Mud2 (Figure 2C and Figure S1D) and Lea1 (Figure 2D and Figure S1E). No change in Mud2 occupancy was observed (Figure 2C and Figure S1D; compare Hmt1 "“+” bars to Hmt1 "-“" bars above myc IP) and a small increase in Lea1 occupancy occurred near the 5'-end of the second ECM33 exon (Figure 2D; compare Hmt1 "+" bars to Hmt1 "“-" bars in primer set A3). In the case of ASC1, the in vivo occupancy by the tested splicing factors (Figure S1B-E) was similar to that for ECM33, except for the observation of an increase in Snp1 occupancy in the downstream regions of $A S C 1$. This observation is consistent with a previously published result showing 
Muddukrishna

increased occupancy for three other U1 snRNP proteins at the same region [22]. As a control, we also examined the recruitment pattern of Snp1 and Npl3 along an intronless gene $P M A 1$ and did not find their occupancies to be affected in $\Delta h m t l$ cells (Figure S2B and $\mathrm{S} 2 \mathrm{C}$ ). Their recruitment patterns along PMA1 were similar to those seen in previously published reports for U1 snRNP [22] and Npl3 [53]. To test for potential differences in transcriptional output that may account for the differences in their recruitment pattern, we measured occupancy of RNA Polymerase II subunit Rpb3 across these genes and found no difference between HMT1 and $\Delta h m t 1$ cells (Figure $2 \mathrm{E}$ and Figure S1F). To determine whether the difference seen in the recruitment of Np13 and Snp1 is due to the presence of RNA, we incorporated an RNAse treatment step in our ChIP protocol and repeated the ChIP experiment. For both Npl3 and Snp1, the differences observed between HMT1 and $\triangle h m t 1$ cells for ECM33 and SUS1 are no longer present (Figure 2F-G). Thus, Hmt1 plays a role in promoting optimal level of cotranscriptional recruitment for Snp1 and Npl3 across intron-containing genes of either consensus or non-consensus splice sites in an RNA-dependent manner.

\subsection{Arginine methylation of $\mathrm{Npl3}$ affects recruitment of Snp1 to intron-containing} genes

Since Hmt 1 is an enzyme that methylates a number of RNA-binding proteins known to play a role in splicing, we wanted to see whether one such substrate, Npl3, is responsible for the differences in the occupancy of splicing factors observed in a $\Delta \mathrm{hmt} 1$ background (Figure 2). To this end, we replaced the genomic copy of NPL3 with the $n p l 3^{R K}$ mutant in our strains with myc-tagged splicing factors. $\mathrm{Npl}^{\mathrm{RK}}$ is a mutant form of Npl3 in which 15 of the 17 identified Npl3 arginines that undergo arginine methylation 
Muddukrishna

had been mutated to lysines [46]. Substitution of the arginine with lysine retains the positive charge of the arginine residue [54, 55]. Based on characterizations done by other labs, it was revealed that $\mathrm{Npl}^{\mathrm{RK}}$ phenocopies wild-type $\mathrm{Npl3}$ behavior when expressed in $\Delta h m t 1$ cells $[46,55,56]$. Thus, the use of $\mathrm{Npl} 3^{\mathrm{RK}}$ mutant makes it possible for us to probe the specific impact of wild-type Npl3 in isolation.

We tested $\mathrm{Npl}^{\mathrm{RK}}$ occupancy across the same intron-containing genes in both $H M T 1$ and $\Delta h m t 1$ cells (Figure 3 and Figure S3) and, as expected, the expression of $\mathrm{Npl3}^{\mathrm{RK}}$ in $\Delta h m t 1$ cells restored occupancy of both Npl3 (Figure 3A; compare Hmt1 “+” bars above Npl3 WT to Hmt1 “_“" bars above Npl3 RK) and Snp1 (Figure 3B; compare Hmt1 "+” bars above Npl3 WT to Hmt1 “_" bars above Npl3 RK) to the levels seen in the HMT1 strain for ECM33, SUS1, and ASC1 (Figure S3A and B; compare Hmt1 "+" bars above Np13 WT to Hmt1 “_“" bars above Npl3 RK). Similar as Npl3 and Snp1, recruitment of Lea1 across the same three intron-containing genes in $\Delta h m t 1$ cells expressing $\mathrm{Npl} 3^{\mathrm{RK}}$ was restored to the level seen in $H M T 1$ cells (Figure $3 \mathrm{C}$ and Figure S3D, compare Hmt1 “+” bars above Np13 WT to Hmt1 “_“ bars above Np13 RK). Thus, we attribute the changes in the recruitment pattern for Snp1, Npl3, and Lea1 to the lack of Npl3 arginine methylation in $\Delta h m t 1$ cells.

\subsection{Loss of Hmt1 results in decreased splicing of pre-mRNAs harboring non- consensus splice sites}

We inferred that the observed changes in in vivo occupancy of intron-containing genes by splicing factors affect the efficiency of splicing of transcripts produced from the tested intron-containing genes above. To test this hypothesis, we assessed the splicing efficiency of these transcripts at $30^{\circ} \mathrm{C}$ and $22^{\circ} \mathrm{C}$ by RT-qPCR, based on the percentage of 
Muddukrishna

intron spliced, as previously described [57]. For ECM33 (Figure 4A) and ASC1 (Figure S4A) pre-mRNAs, we observed no difference in their efficiency of splicing between HMT1 and $\triangle 4 m t 1$ cells (Figure 4A; compare Hmt1 “+” to Hmt1 “_“ bars above Npl3 WT; and Figure S4A; compare Hmt1 “+” to Hmt1 “-“ bars). In contrast, loss of Hmt1 affected the efficiency of splicing of the first intron of $S U S 1$ pre-mRNA at both $30^{\circ} \mathrm{C}$ and $22^{\circ} \mathrm{C}$ (Figure 4B; SUS1 (Intron 1) panel, compare Hmt1 “+” to Hmt1 “_“" bars above Npl3 WT). Notably, the second intron of the SUS1 pre-mRNA, which harbors consensus 5' splice site and branch site, did not display an Hmt1-dependent decrease in splicing efficiency at these temperatures (Figure 4B; SUS1 (Intron 2) panel, compare Hmt1 "+" to Hmt1 “_“ bars above Npl3 WT). Thus, our data implicate a role for Hmt1 in promoting efficient splicing of introns with a non-consensus 5' splice site and a branch site, but not those with consensus sequences.

\subsection{Requirement of $\mathrm{Npl3}$ arginine methylation for efficient splicing of the $S U S 1$ pre-mRNAs}

In mammalian cells, the SR proteins stabilize the association between the U1 snRNP and the 5' splice site [58], and they are thought to function by binding to exonic sequences adjacent to suboptimal SS and promoting recruitment of the U1 and U2 snRNPs. While the budding yeast lacks homologs of these SR proteins, Npl3, a substrate of Hmt1 [44, 45], is considered an SR-like protein [26, 59]. Previously, Npl3 has been shown to physically association with the U1 snRNP on the chromatin and facilitates splicing of a specific set of intron-containing transcripts [57]. Thus, we hypothesized that the arginine methylation of Npl3 may be critical for efficient splicing of introns with nonconsensus splice sites. To probe the impact of $\mathrm{Npl} 3$ arginine methylation on the splicing 
efficiency of the same intron-containing transcripts, we expressed $\mathrm{Np}^{\mathrm{RK}}$ in the $H M T 1$ and $\Delta h m t 1$ backgrounds, as $\mathrm{Npl} 3^{\mathrm{RK}}$ phenocopies wild-type $\mathrm{Npl3}$ behavior when expressed in the $\Delta h m t 1$ background.

Employing the same RT-qPCR approach, we found that the efficiency of splicing of the ECM33 pre-mRNA did not differ between the HMTl and $\triangle h m t 1$ cells expressing $\mathrm{Npl}^{\mathrm{RK}}$ (Figure 4A; compare the bars in Hmt1 “_“" above Npl3 RK to Hmt1 “+” above Npl3 WT). In the case of SUS1 intron 1, the expression of $\mathrm{Npl}^{\mathrm{RK}}$ in $\Delta h m t 1$ cells restored the efficiency of pre-mRNA splicing to a similar level as those in the HMT1 background with wild-type Npl3 expression (Figure 4B; compare the bars in Hmt1 "_“ above Npl3 RK to Hmt1 “+” above Npl3 WT in SUS1 (Intron 1) panel). Similar to ECM33, expressing $\mathrm{Npl} 3^{\mathrm{RK}}$ in $\Delta h m t 1$ cells does not affect the efficiency of splicing of SUS1 intron 2 (Figure 4B, compare the bars in Hmt1 “_“" above Npl3 RK to Hmt1 "+” above Npl3 WT in SUS1 (Intron 2) panel). The same is true for ASC1 (Figure S4B). Thus, the use of an $\mathrm{Npl} 3^{\mathrm{RK}}$ mutant that phenocopies wild-type $\mathrm{Npl} 3$ behavior when expressed in $\Delta h m t 1$ cells allows us to conclude that arginine methylation of $\mathrm{Npl} 3$ positively influences the splicing of SUS1 intron 1.

\subsection{Changing a non-consensus splice site in $S U S 1$ to its consensus counterpart rescues splicing efficiency in the $\Delta h m t 1$ background}

Whereas the introns of both ECM33 and ASC1 have consensus 5' splice site (GUAUGU) and branch site sequences (UACUAAC), the first intron of SUS1 has a nonconsensus 5' splice site (GUAUGA) and branch site sequence (UACUGAC) (Figure 1A). To determine if Hmt1 plays a role in the splicing of pre-mRNAs containing nonconsensus splice sites, we mutated the non-consensus 5' splice site and the branch site 
Muddukrishna

sequence in the SUS1 intron 1 to the consensus sequence and ectopically expressed this clone (Figure $5 \mathrm{~A}$ ) in a $\Delta s u s 1$ strain. We then determined the efficiency of splicing of SUS1 intron 1 in this strain by RT-qPCR as described above (Figure 5B, CONS lanes). The SUS1 intron 1 with a consensus 5' splice site and branch site sequence was more efficiently spliced than its wild-type, non-consensus counterpart in both HMT1 and $\Delta h m t 1$ backgrounds at both temperatures tested (Figure 5B; compare WT to CONS lanes). Thus, the splicing efficiency of this modified SUS1 construct is refractory to Hmt1 status, similar to what was observed with ECM33 and ASC1. These data support a role for Hmt1 in promoting the utilization of a non-consensus 5' splice site and branch site by the spliceosome.

\subsection{Methylation of $\mathrm{Npl3}$ does not directly affect its binding to SUS1 RNA}

Arginine methylation has previously been implicated as a means of regulating how a substrate interacts with nucleic acids and proteins $[60,61]$. Since Npl3 is an RNAbinding protein that harbors RRM motifs [62], we hypothesize that a mechanism by which Hmt1-mediated methylation of Npl3 affects pre-mRNA splicing of SUS1 may be through its ability to bind SUSI pre-mRNA. To this end, we tested the RNA-binding capacity of recombinant Npl3 containing either methylated or unmethylated arginines that were generated by an E. coli co-expression system similar to the one described previously [63]. Based on the pattern of migration shift of recombinant Npl3 in the immunoblot, we conclude that these recombinant Npl3 proteins are likely all fully methylated. We then performed an electrophoretic gel mobility shift assay (EMSA) with the recombinant methylated or unmethylated $\mathrm{Npl3}$ and in vitro transcribed SUS1 (Figure S5A). Binding of both forms of Npl3 to the tested RNA was robust and specific, as 
Muddukrishna

determined by competition experiments with either specific or non-specific competitors (Figure S5B). We did not detect any significant differences in the binding of methylated versus unmethylated Npl3 to SUS1 under any of the several experimental conditions. Thus, methylation of Npl3 does not affect its direct binding to SUS1 RNA and likely affects SUS1 pre-mRNA splicing via perturbing its interaction with a protein partner.

\subsection{Methylation of $\mathrm{Npl3}$ is critical for specific interaction with Mud1, a subunit of the U1 snRNP}

To determine if the methylation status of $\mathrm{Npl} 3$ affects the interaction between Npl3 and the U1 snRNP, we performed a pulldown experiment with immobilized methylated or unmethylated $\mathrm{Npl3}$, measuring the amount of snRNA as a readout for snRNPs associated with Npl3 (Figure 6A; bars above U1). We detected more U1 snRNA in the pulldown with unmethylated Npl3 versus methylated Npl3, suggesting that methylation promotes the dissociation between U1 snRNPs and Npl3 (Figure 6A; compare the bar from Npl3 methylation "+” to Npl3 methylation “_“ above U1). This effect is specific for the U1; no notable difference in pulldown of either U2 or U4 snRNAs was observed when using methylated versus unmethylated Npl3 (Figure 6A; compare the bar from Npl3 methylation “+” to Npl3 methylation “_“ above U2 and U4).

Having demonstrated that the methylation of Npl3 interferes with its interaction with the U1 snRNP, we sought to determine which subunit(s) mediates this interaction. We first expressed and purified individual U1 snRNP subunits as GST fusion constructs in $E$. coli, and then tested their individual interactions with methylated or unmethylated Npl3 (Figure 6B). For Luc7 or Nam8, we did not detect any interaction (Figure 6B; GST-Luc7 and GST-Nam8 panels, compare the band intensities from Npl3 "+ lanes to 
Muddukrishna

Npl3 “_“ lanes under GST-Protein Pulldown). The interaction between Npl3 and the U1 snRNP subunit Snu56 was not affected by methylation (Figure 6B; GST-Snu56 panel, compare the band intensities from Npl3 “+ lanes to Npl3 “_“ lanes under GST-Protein Pulldown) whereas the interaction with Snp1 and Yhc1 were slightly increased (Figure 6B; GST-Snp1 and GST-Yhc1 panels; compare the band intensities from Npl3 "+ lanes to Np13 “_" lanes under GST-Protein Pulldown). The greatest change in the level of interaction was detected for Mud1 and unmethylated Npl3 relative to Mud1 and methylated Npl3 (Figure 6B; GST-Mud1 panel; compare the band intensities from Npl3 “+ lanes to Npl3 “_" lanes under GST-Protein Pulldown). Thus, arginine methylation of $\mathrm{Npl} 3$ is critical for its interaction with the U1 snRNP, and this is likely accomplished via its association with Mud1.

\section{Discussion}

The splicing architecture in the budding yeast is simple relative to that of metazoans, and yeast introns conform to tight consensus sequences at their splice sites. One outstanding question with respect to the yeast splicing machinery is whether it is capable of regulating splice-site selection, with an implication that such regulation could impact gene expression. The presence of non-consensus splice-site sequences at certain intron-containing genes supports the hypothesis that the yeast splicing machinery is capable of regulating splice-site selection. One potential means by which yeast splicing machinery can regulate splice site selection is by post-translational modifications on core components of the spliceosome or proteins that interact with the spliceosome. Our present work demonstrates that Hmt 1 promotes the spliceosome usage of non-consensus splice sites in SUS1 intron 1. This is in contrast to ECM33, ASC1, and SUS1 intron 2, all 
of which harbors a consensus 5' splice site and branch site (Figure 1A). When the nonconsensus 5' splice site and branch site were changed back to consensus in SUS1 intron 1, its splicing efficiency in $\Delta h m t 1$ cells was restored to the level seen in $H M T l$ cells and refractory to Hmt1-status, further supporting a role for Hmt1 in promoting utilization of a non-consensus 5' splice site and branch site by the spliceosome.

In addition to having its majority of splice sites conform to a strict consensus, most of the intron-containing genes in the budding yeast contains only a single intron and do not undergo alternative splicing. This may explain a lack of SR proteins and hnRNPs that normally control transcript-specific splicing in higher eukaryotes. In mammalian cells, SR proteins play key regulatory roles in constitutive and alternative splicing [27, 28, 64-66]. These proteins have a modular domain structure, including one or more RNA recognition motifs (RRMs), as well as a C-terminal RS domain that is enriched for arginine and serine residues, which are often sites of post-translational modifications. SR proteins stabilize the association between the U1 snRNP and the 5' splice site [58], and they are thought to function by binding to exonic sequences adjacent to suboptimal splice sites and promoting recruitment of the $\mathrm{U} 1$ and $\mathrm{U} 2$ snRNPs. Npl3 is an SR-like protein $[26,59]$ that shares structural features with members of the hnRNP family [67-69]. It has two RRMs and a C-terminal domain that contains multiple RGG tripeptides and RG dipeptides. The vast majority of aDMAs of Npl3 are present within the RGG context [46]. As Npl3 is required for the splicing of a subset of pre-mRNAs [57], we posited that Hmt1-mediated methylation of $\mathrm{Npl} 3$ could be a means of regulating the splicing efficiency of pre-mRNAs with non-consensus splice sites. Employing a previously characterized $\mathrm{Npl} 3$ mutant $\left(\mathrm{Npl} 3^{\mathrm{RK}}\right)$ that phenocopies wild-type $\mathrm{Npl} 3$ when expressed in 
a $\Delta h m t 1$ background $[46,55,56]$, we demonstrated that Hmt1, via its methylation of Npl3, promotes efficient splicing of SUS1 intron 1. When expressed in a $\triangle \mathrm{hmtl}$ background, $\mathrm{Npl} 1{ }^{\mathrm{RK}}$ mutant mimics wild-type $\mathrm{Npl3}$ behavior in its subcellular localization and protein-protein interactions $[46,56]$. In our present study, we further show that the co-transcriptional profile for $\mathrm{Npl}^{\mathrm{RK}}$, when expressed in $\Delta h m t 1$ background, mimics wild-type Npl3. A similar approach was previously employed to study the mammalian SR-protein SF2/ASF, which is a substrate of human PRMT1 [70]. Characterization of a SF2/ASF triple point mutant in which the three identified methylarginines were replaced by lysines revealed this mutant to be functionally indistinguishable from wild-type SF2/ASF in its ability to carry out general and alternative splicing in vitro [70]. Thus, the use of $\mathrm{Npl}^{\mathrm{RK}}$ mutant makes it possible for us to probe the specific impact of wild-type $\mathrm{Npl3}$ in isolation and define what contributes to the co-transcriptional recruitment and splicing efficiency phenotypes observed in $\Delta \mathrm{hmtl}$ cells.

Protein arginine methylation has been known to play a key role in the proteinnucleic acids and protein-protein interactions [71-73], as methylation of the terminal amino group in the arginine side chain does not alter its positive charge but increases the hydrophobicity, resulting in a bulkier side chain and thereby blocking any potential formation of hydrogen bonds. Our RNA gel shift assays indicate that arginine methylation of Npl3 does not impact its ability to associate with SUS1 introns (Figure S5). Turning our attention to its potential impact on protein-protein interactions, our in vitro data shows an increased biochemical association between unmethylated Npl3 and the $\mathrm{U} 1$ snRNP, relative to methylated $\mathrm{Npl} 3$ and the $\mathrm{U} 1 \mathrm{snRNP}$, and this observation is 
made only with the U1 snRNP, not U2 nor U4 snRNP (Figure 6A). Subsequent pairwise testing with individual U1 snRNP subunits revealed that Mud1, the yeast homolog of human U1-A, is the subunit that demonstrates an increased association with unmethylated $\mathrm{Npl3}$, relative to its association with methylated Npl3 (Figure 6B). Mud1 is a subunit of the U1 snRNP and is important for 5' splice site selection and the splicing efficiency of intron-containing transcripts in yeast $[74,75]$. In vivo splicing efficiency assays using intron-containing reporters have shown that yeast cells with defective Mud1 adversely affect splicing of an inefficient intron-containing reporter versus that of an efficient spliced intron-containing reporters [76]. Therefore, it is possible that the methylation of Npl3 plays an important role in promoting how U1 snRNP engages with the pre-mRNA via its interaction with Mud1. Further experiments will need to be carried out in order to better understand the mechanistic details of how arginine methylation of $\mathrm{Npl} 3$ impacts Mud1 function within the U1 snRNP.

Many post-translational modifications of spliceosomal components have been reported, but both the mechanism whereby these modifications of the splicing factors are regulated and their functional consequences for pre-mRNA splicing remain obscure. The work we report here provides insight into how one such modification controls pre-mRNA splicing. We predict that the establishment of this yeast mechanism will facilitate the analysis of similar mechanisms in higher eukaryotes, given the strong conservation of PRMT-mediated arginine methylation in mammalian cells. 


\section{$\underline{\text { Acknowledgements }}$}

We thank Anne McBride for Npl3 ${ }^{\mathrm{RK}}$ constructs, Laura Rusche for critical reading of the manuscript, and members of the Yu laboratory for helpful discussions. This work was supported by a National Science Foundation award (MCB-1051350) to M.C.Y. 


\section{References}

[1] U. Braunschweig, S. Gueroussov, A.M. Plocik, B.R. Graveley, B.J. Blencowe, Dynamic integration of splicing within gene regulatory pathways, Cell, 152 (2013) 12521269.

[2] J. Han, J. Xiong, D. Wang, X.D. Fu, Pre-mRNA splicing: where and when in the nucleus, Trends Cell Biol, 21 (2011) 336-343.

[3] M.C. Wahl, C.L. Will, R. Lührmann, The spliceosome: design principles of a dynamic RNP machine., Cell, 136 (2009) 701-718.

[4] C.L. Will, R. Lührmann, Spliceosome structure and function., Cold Spring Harbor perspectives in biology, 3 (2011).

[5] Y. Zhuang, A.M. Weiner, A compensatory base change in U1 snRNA suppresses a 5' splice site mutation, Cell, 46 (1986) 827-835.

[6] P.G. Siliciano, C. Guthrie, 5' splice site selection in yeast: genetic alterations in basepairing with U1 reveal additional requirements, Genes \& development, 2 (1988) 12581267.

[7] B. Séraphin, L. Kretzner, M. Rosbash, A U1 snRNA:pre-mRNA base pairing interaction is required early in yeast spliceosome assembly but does not uniquely define the 5\&apos; cleavage site., The EMBO journal, 7 (1988) 2533-2538.

[8] N. Abovich, M. Rosbash, Cross-intron bridging interactions in the yeast commitment complex are conserved in mammals, Cell, 89 (1997) 403-412.

[9] N. Abovich, X.C. Liao, M. Rosbash, The yeast MUD2 protein: an interaction with PRP11 defines a bridge between commitment complexes and U2 snRNP addition., Genes \& development, 8 (1994) 843-854.

[10] Q. Wang, L. Zhang, B. Lynn, B.C. Rymond, A BBP-Mud2p heterodimer mediates branchpoint recognition and influences splicing substrate abundance in budding yeast., Nucleic acids research, 36 (2008) 2787-2798.

[11] J.A. Berglund, K. Chua, N. Abovich, R. Reed, M. Rosbash, The splicing factor BBP interacts specifically with the pre-mRNA branchpoint sequence UACUAAC, Cell, 89 (1997) 781-787.

[12] A.L. Kistler, C. Guthrie, Deletion of MUD2, the yeast homolog of U2AF65, can bypass the requirement for sub2, an essential spliceosomal ATPase, Genes \& development, 15 (2001) 42-49.

[13] W.W. Liang, S.C. Cheng, A novel mechanism for Prp5 function in prespliceosome formation and proofreading the branch site sequence, Genes \& development, 29 (2015) 81-93. 
[14] C.L. O'Day, G. Dalbadie-McFarland, J. Abelson, The Saccharomyces cerevisiae Prp5 protein has RNA-dependent ATPase activity with specificity for U2 small nuclear RNA, The Journal of biological chemistry, 271 (1996) 33261-33267.

[15] G.M. Lamm, B.J. Blencowe, B.S. Sproat, A.M. Iribarren, U. Ryder, A.I. Lamond, Antisense probes containing 2-aminoadenosine allow efficient depletion of U5 snRNP from HeLa splicing extracts, Nucleic acids research, 19 (1991) 3193-3198.

[16] B. Seraphin, N. Abovich, M. Rosbash, Genetic depletion indicates a late role for U5 snRNP during in vitro spliceosome assembly, Nucleic acids research, 19 (1991) 38573860 .

[17] A. Bindereif, M.R. Green, An ordered pathway of snRNP binding during mammalian pre-mRNA splicing complex assembly, The EMBO journal, 6 (1987) 24152424.

[18] M.M. Konarska, P.A. Sharp, Interactions between small nuclear ribonucleoprotein particles in formation of spliceosomes, Cell, 49 (1987) 763-774.

[19] J.P. Staley, C. Guthrie, An RNA switch at the 5\&apos; splice site requires ATP and the DEAD box protein Prp28p., Molecular cell, 3 (1999) 55-64.

[20] H.D. Madhani, C. Guthrie, A novel base-pairing interaction between U2 and U6 snRNAs suggests a mechanism for the catalytic activation of the spliceosome, Cell, 71 (1992) 803-817.

[21] S.P. Chan, D.I. Kao, W.Y. Tsai, S.C. Cheng, The Prp19p-associated complex in spliceosome activation, Science, 302 (2003) 279-282.

[22] K.M. Kotovic, D. Lockshon, L. Boric, K.M. Neugebauer, Cotranscriptional recruitment of the U1 snRNP to intron-containing genes in yeast, Molecular and cellular biology, 23 (2003) 5768-5779.

[23] S.A. Lacadie, M. Rosbash, Cotranscriptional spliceosome assembly dynamics and the role of U1 snRNA:5'ss base pairing in yeast, Molecular cell, 19 (2005) 65-75.

[24] M.J. Moore, E.M. Schwartzfarb, P.A. Silver, M.C. Yu, Differential recruitment of the splicing machinery during transcription predicts genome-wide patterns of mRNA splicing., Molecular cell, 24 (2006) 903-915.

[25] K.M. Neugebauer, On the importance of being co-transcriptional, Journal of cell science, 115 (2002) 3865-3871.

[26] C.W. Siebel, L. Feng, C. Guthrie, X.D. Fu, Conservation in budding yeast of a kinase specific for SR splicing factors, Proceedings of the National Academy of Sciences of the United States of America, 96 (1999) 5440-5445. 
[27] Z. Zhou, X.D. Fu, Regulation of splicing by SR proteins and SR protein-specific kinases, Chromosoma, 122 (2013) 191-207.

[28] J.C. Long, J.F. Caceres, The SR protein family of splicing factors: master regulators of gene expression, The Biochemical journal, 417 (2009) 15-27.

[29] B.J. Blencowe, J.A. Bowman, S. McCracken, E. Rosonina, SR-related proteins and the processing of messenger RNA precursors, Biochem Cell Biol, 77 (1999) 277-291.

[30] W. Gilbert, C.W. Siebel, C. Guthrie, Phosphorylation by Sky1p promotes Npl3p shuttling and mRNA dissociation., RNA (New York, NY), 7 (2001) 302-313.

[31] G. Dreyfuss, M.J. Matunis, S. Pinol-Roma, C.G. Burd, hnRNP proteins and the biogenesis of mRNA, Annu Rev Biochem, 62 (1993) 289-321.

[32] S.P. Han, Y.H. Tang, R. Smith, Functional diversity of the hnRNPs: past, present and perspectives, The Biochemical journal, 430 (2010) 379-392.

[33] S.L. McKay, T.L. Johnson, A bird's-eye view of post-translational modifications in the spliceosome and their roles in spliceosome dynamics, Molecular bioSystems, 6 (2010) 2093-2102.

[34] P. Bellare, E.C. Small, X. Huang, J.A. Wohlschlegel, J.P. Staley, E.J. Sontheimer, A role for ubiquitin in the spliceosome assembly pathway., Nature Structural \&\#38; Molecular Biology, 15 (2008) 444-451.

[35] Y.-C. Chen, E.J. Milliman, I. Goulet, J. Côté, C.A. Jackson, J.A. Vollbracht, M.C. $\mathrm{Yu}$, Protein arginine methylation facilitates cotranscriptional recruitment of pre-mRNA splicing factors., Molecular and cellular biology, 30 (2010) 5245-5256.

[36] R. Sinha, E. Allemand, Z. Zhang, R. Karni, M.P. Myers, A.R. Krainer, Arginine methylation controls the subcellular localization and functions of the oncoprotein splicing factor SF2/ASF., Molecular and cellular biology, 30 (2010) 2762-2774.

[37] A.P. Snijders, G.M. Hautbergue, A. Bloom, J.C. Williamson, T.C. Minshull, H.L. Phillips, S.R. Mihaylov, D.T. Gjerde, D.P. Hornby, S.A. Wilson, P.J. Hurd, M.J. Dickman, Arginine methylation and citrullination of splicing factor proline- and glutamine-rich (SFPQ/PSF) regulates its association with mRNA, Rna, 21 (2015) 347359.

[38] S.E. Sanchez, E. Petrillo, E.J. Beckwith, X. Zhang, M.L. Rugnone, C.E. Hernando, J.C. Cuevas, M.A. Godoy Herz, A. Depetris-Chauvin, C.G. Simpson, J.W.S. Brown, P.D. Cerdán, J.O. Borevitz, P. Mas, M.F. Ceriani, A.R. Kornblihtt, M.J. Yanovsky, A methyl transferase links the circadian clock to the regulation of alternative splicing., Nature, 468 (2010) 112-116.

[39] M. Bezzi, S.X. Teo, J. Muller, W.C. Mok, S.K. Sahu, L.A. Vardy, Z.Q. Bonday, E. Guccione, Regulation of constitutive and alternative splicing by PRMT5 reveals a role 
for Mdm4 pre-mRNA in sensing defects in the spliceosomal machinery, Genes \& development, 27 (2013) 1903-1916.

[40] M.T. Bedford, S. Richard, Arginine methylation an emerging regulatorof protein function, Molecular cell, 18 (2005) 263-272.

[41] G. Meister, C. Eggert, D. Buhler, H. Brahms, C. Kambach, U. Fischer, Methylation of Sm proteins by a complex containing PRMT5 and the putative U snRNP assembly factor pICln, Current biology : CB, 11 (2001) 1990-1994.

[42] W.J. Friesen, S. Paushkin, A. Wyce, S. Massenet, G.S. Pesiridis, G. van Duyne, J. Rappsilber, M. Mann, G. Dreyfuss, The methylosome, a 20S complex containing JBP1 and $\mathrm{pICln}$, produces dimethylarginine-modified Sm proteins, Molecular and cellular biology, 21 (2001) 8289-8300.

[43] J.D. Gary, W.J. Lin, M.C. Yang, H.R. Herschman, S. Clarke, The predominant protein-arginine methyltransferase from Saccharomyces cerevisiae., The Journal of biological chemistry, 271 (1996) 12585-12594.

[44] M.F. Henry, P.A. Silver, A novel methyltransferase (Hmt1p) modifies poly(A)+RNA-binding proteins, Molecular and cellular biology, 16 (1996) 3668-3678.

[45] C.W. Siebel, C. Guthrie, The essential yeast RNA binding protein Npl3p is methylated., Proceedings of the National Academy of Sciences of the United States of America, 93 (1996) 13641-13646.

[46] A.E. McBride, J.T. Cook, E.A. Stemmler, K.L. Rutledge, K.A. McGrath, J.A. Rubens, Arginine methylation of yeast mRNA-binding protein Npl3 directly affects its function, nuclear export, and intranuclear protein interactions, The Journal of biological chemistry, 280 (2005) 30888-30898.

[47] M.S. Longtine, A. McKenzie, 3rd, D.J. Demarini, N.G. Shah, A. Wach, A. Brachat, P. Philippsen, J.R. Pringle, Additional modules for versatile and economical PCR-based gene deletion and modification in Saccharomyces cerevisiae, Yeast (Chichester, England), 14 (1998) 953-961.

[48] M. Knop, K. Siegers, G. Pereira, W. Zachariae, B. Winsor, K. Nasmyth, E. Schiebel, Epitope tagging of yeast genes using a PCR-based strategy: more tags and improved practical routines, Yeast (Chichester, England), 15 (1999) 963-972.

[49] M.C. Yu, F. Bachand, A.E. McBride, S. Komili, J.M. Casolari, P.A. Silver, Arginine methyltransferase affects interactions and recruitment of mRNA processing and export factors, Genes \& development, 18 (2004) 2024-2035.

[50] E.P. Lei, P.A. Silver, Intron status and 3'-end formation control cotranscriptional export of mRNA, Genes \& development, 16 (2002) 2761-2766. 
[51] H.E. Klock, E.J. Koesema, M.W. Knuth, S.A. Lesley, Combining the polymerase incomplete primer extension method for cloning and mutagenesis with microscreening to accelerate structural genomics efforts, Proteins, 71 (2008) 982-994.

[52] M. Spingola, L. Grate, D. Haussler, M. Ares, Genome-wide bioinformatic and molecular analysis of introns in Saccharomyces cerevisiae., RNA (New York, NY), 5 (1999) 221-234.

[53] E.P. Lei, H. Krebber, P.A. Silver, Messenger RNAs are recruited for nuclear export during transcription, Genes \& development, 15 (2001) 1771-1782.

[54] J. Najbauer, B.A. Johnson, A.L. Young, D.W. Aswad, Peptides with sequences similar to glycine, arginine-rich motifs in proteins interacting with RNA are efficiently recognized by methyltransferase(s) modifying arginine in numerous proteins, The Journal of biological chemistry, 268 (1993) 10501-10509.

[55] C. XU, M.F. Henry, Nuclear Export of hnRNP Hrplp and Nuclear Export of hnRNP Npl3p Are Linked and Influenced by the Methylation State of Npl3p, Molecular and cellular biology, 24 (2004) 10742-10756.

[56] C.M. Wong, H.M. Tang, K.Y. Kong, G.W. Wong, H. Qiu, D.Y. Jin, A.G. Hinnebusch, Yeast arginine methyltransferase Hmtlp regulates transcription elongation and termination by methylating Npl3p, Nucleic acids research, 38 (2010) 2217-2228.

[57] T.L. Kress, N.J. Krogan, C. Guthrie, A single SR-like protein, Npl3, promotes premRNA splicing in budding yeast., Molecular cell, 32 (2008) 727-734.

[58] J.Y. Wu, T. Maniatis, Specific interactions between proteins implicated in splice site selection and regulated alternative splicing, Cell, 75 (1993) 1061-1070.

[59] E. Birney, S. Kumar, A.R. Krainer, Analysis of the RNA-recognition motif and RS and RGG domains: conservation in metazoan pre-mRNA splicing factors., Nucleic acids research, 21 (1993) 5803-5816.

[60] M.T. Bedford, S.G. Clarke, Protein arginine methylation in mammals: who, what, and why, Molecular cell, 33 (2009) 1-13.

[61] J.E. Beaver, M.L. Waters, Molecular Recognition of Lys and Arg Methylation, ACS chemical biology, 11 (2016) 643-653.

[62] M.A. Bossie, C. DeHoratius, G. Barcelo, P. Silver, A mutant nuclear protein with similarity to RNA binding proteins interferes with nuclear import in yeast, Molecular biology of the cell, 3 (1992) 875-893.

[63] C.-H. Hsieh, S.-Y. Huang, Y.-C. Wu, L.-F. Liu, C.-C. Han, Y.-C. Liu, M.F. Tam, Expression of proteins with dimethylarginines in Escherichia coli for protein-protein interaction studies., Protein science : a publication of the Protein Society, 16 (2007) 919928. 
[64] X.Y. Zhong, P. Wang, J. Han, M.G. Rosenfeld, X.D. Fu, SR proteins in vertical integration of gene expression from transcription to RNA processing to translation, Molecular cell, 35 (2009) 1-10.

[65] K.J. Hertel, B.R. Graveley, RS domains contact the pre-mRNA throughout spliceosome assembly, Trends in biochemical sciences, 30 (2005) 115-118.

[66] J.M. Howard, J.R. Sanford, The RNAissance family: SR proteins as multifaceted regulators of gene expression, Wiley interdisciplinary reviews. RNA, 6 (2015) 93-110.

[67] G. Dreyfuss, V.N. Kim, N. Kataoka, Messenger-RNA-binding proteins and the messages they carry, Nature reviews. Molecular cell biology, 3 (2002) 195-205.

[68] I. Russell, D. Tollervey, Yeast Nop3p has structural and functional similarities to mammalian pre-mRNA binding proteins, European journal of cell biology, 66 (1995) 293-301.

[69] M. Henry, C.Z. Borland, M. Bossie, P.A. Silver, Potential RNA binding proteins in Saccharomyces cerevisiae identified as suppressors of temperature-sensitive mutations in NPL3, Genetics, 142 (1996) 103-115.

[70] R. Sinha, E. Allemand, Z. Zhang, R. Karni, M.P. Myers, A.R. Krainer, Arginine methylation controls the subcellular localization and functions of the oncoprotein splicing factor SF2/ASF, Molecular and cellular biology, 30 (2010) 2762-2774.

[71] M.T. Bedford, A. Frankel, M.B. Yaffe, S. Clarke, P. Leder, S. Richard, Arginine methylation inhibits the binding of proline-rich ligands to Src homology 3, but not WW, domains, The Journal of biological chemistry, 275 (2000) 16030-16036.

[72] M.C. Yu, F. Bachand, A.E. McBride, S. Komili, J.M. Casolari, P.A. Silver, Arginine methyltransferase affects interactions and recruitment of mRNA processing and export factors., Genes \& development, 18 (2004) 2024-2035.

[73] J. Côté, S. Richard, Tudor domains bind symmetrical dimethylated arginines., The Journal of biological chemistry, 280 (2005) 28476-28483.

[74] T. Kawashima, S. Douglass, J. Gabunilas, M. Pellegrini, G.F. Chanfreau, Widespread Use of Non-productive Alternative Splice Sites in Saccharomyces cerevisiae, PLoS genetics, 10 (2014) e1004249.

[75] J. Tang, M. Rosbash, Characterization of yeast U1 snRNP A protein: identification of the N-terminal RNA binding domain (RBD) binding site and evidence that the Cterminal RBD functions in splicing, Rna, 2 (1996) 1058-1070.

[76] X.C. Liao, J. Tang, M. Rosbash, An enhancer screen identifies a gene that encodes the yeast U1 snRNP A protein: implications for snRNP protein function in pre-mRNA splicing, Genes \& development, 7 (1993) 419-428. 


\section{Figure and Table Legends}

Figure 1: Schematic representation of the intron-containing genes used in chromatin immunoprecipitation (ChIP) experiments.

(A) For the ChIP experiments described in this study, the primer sets used for qPCR detection of specific regions within the intron-containing genes ECM33 and SUS1 are denoted by corresponding letters and numbers.

(B) The consensus sequences of the yeast splice sites, compared to the ones present in the intron-containing genes ECM33 and SUS1. The red colored nucleotide highlights the difference of such nucleotide from the consensus sequence.

Figure 2: Co-transcriptional recruitment of snRNP subunit and snRNP-associated proteins to intron-containing genes is altered in $\Delta h m t 1$ cells qPCR results for products of chromatin immunoprecipitation, performed on either wildtype or $\Delta h m t 1$ cells using an $\alpha$-myc antibody (9E11) or $\alpha$-human IgG (as a negative control IP). Immunoprecipitated DNA was normalized to input chromatin DNA. (A-D) snRNP subunit and snRNP-associated proteins examined in each panel is indicated. (E) Rpb3 was tested, using an $\alpha-\mathrm{Rpb} 3$ antibody, as a control for RNA polymerase II occupancy. (F-G) An RNAse treatment step was added to the ChIP protocol for Npl3 and Snp1. Letters and numbers (e.g. A1) under the graphs correspond to the specific primer sets indicated in Figure 1A. Percentage of input is calculated by $\Delta \mathrm{C}_{\mathrm{T}}$, with error bars representing standard error of the mean of three biological replicates (n=3). $P$-value: $*<0.05 ;$ and $* *<0.01$.

Figure 3: Arginine methylation of $\mathrm{Npl3}$ promotes proper co-transcriptional recruitment of U1 snRNP subunit Snp1 and SR-like protein Npl3. 
qPCR results for products of chromatin immunoprecipitation performed on NPL3 strains of either the $H M T 1$ or $\triangle h m t l$ background, and $n p l 3 R K$ strains of either the $H M T l$ or Ahmt1 background. (A) Npl3, (B) Snp1, and (C) Lea1. Letters and numbers (e.g. A1) under the graphs correspond to the specific primer sets indicated in Figure 1A. Percentage of input is calculated by $\Delta \mathrm{C}_{\mathrm{T}}$, with error bars representing SEM of three biological samples $(\mathrm{n}=3) . P$-value: $*<0.05 ; * *<0.01$, and $* * *<0.001$.

Figure 4: Arginine methylation of Npl3 promotes efficient splicing of the SUS1 intron harboring a non-consensus 5' splice site and branch site. Pre-mRNA splicing efficiency of ECM33 (A) and both SUS1 introns (B) is determined by qPCR on reverse-transcribed total RNA from yeast cells of either HMTl or $\Delta h m t 1$ background expressing either Npl3 (WT) or $\mathrm{Npl}^{\mathrm{RK}}$ (RK). Percentage of introns spliced was determined by $\Delta \mathrm{C}_{\mathrm{T}}$ after efficiency correction between an exonic primer pair and an intronic primer pair, and shown as a bar graph. Cultures were grown at $30^{\circ} \mathrm{C}$ and $22^{\circ} \mathrm{C}$. Error bars represent the SEM of three biological replicates (n=3). $P$-value: $*<0.05$ and $* *<0.01$.

\section{Figure 5: Replacement SUS1 intron 1 non-consensus 5' splice site and branch site} with consensus sequences restores its efficient splicing independent of Hmt1 (A) Comparison of yeast consensus 5' splice site and branch site to that of SUS1 intron 1. Underlined SUS1 bases have been mutated to the consensus sequence shown above. (B) Splicing efficiency of SUS1 (WT) and SUS1 (CONS; with the SUS1 bases in the 5' splice site and branch site in intron 1 mutated to the consensus sequence) as quantified by qPCR on reverse-transcribed total cellular RNA as in Figure 4. Error bars represent the SEM of three biological replicates $(\mathrm{n}=3) . P$-value: $*<0.05$. 
Figure 6: Arginine methylation of Npl3 plays a role in its biochemical association with the U1 snRNP.

(A) qPCR results of U-snRNA levels from either methylated or unmethylated Npl3

pulldown of yeast whole-cell extract are shown. The results were normalized to a spikedin control RNA, and then to input RNA. The negative controls are beads only.

(B) Individual GST-tagged U1 snRNP subunit was immobilized on GSH-magnetic beads and used as bait for pulldown with methylated or unmethylated Npl3. The methylated and unmethylated Npl3 pulldown signals are quantitated and the $\log _{2}$ ratio of the two signals is shown. A negative ratio indicate that unmethylated Npl3 interacts more strongly with the bait protein than methylated Npl3; a positive ratio indicates that methylated Npl3 interacts more strongly than unmethylated $\mathrm{Npl3}$, and a ratio near 0 indicates that the level of interaction is the same. 
A)

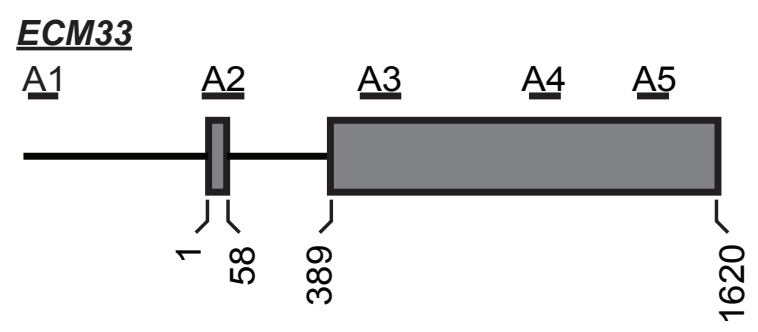

\section{SUS1}

B1 B2

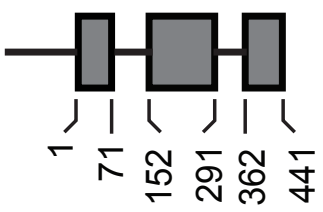

B)

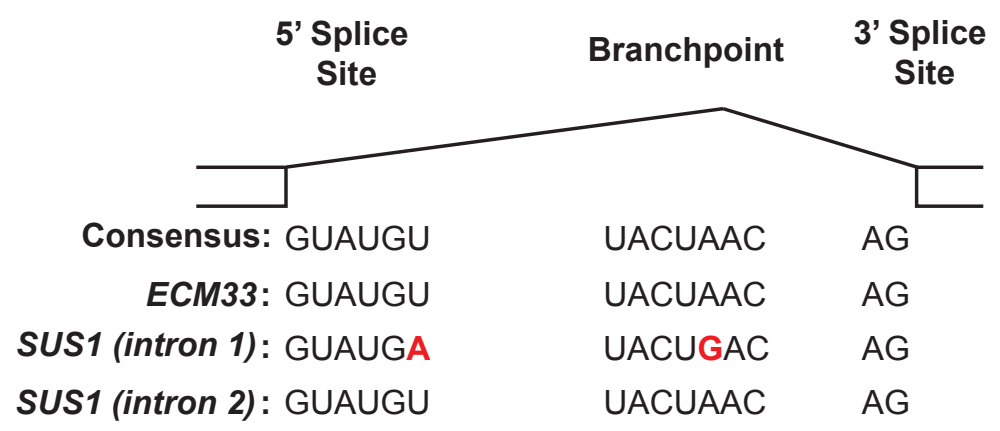


Muddukrishna Figure 2

A)
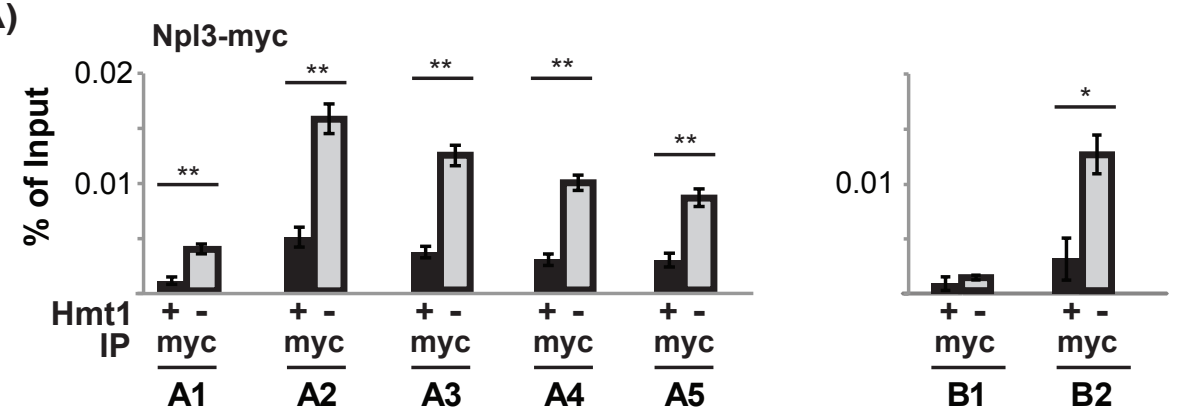

B)
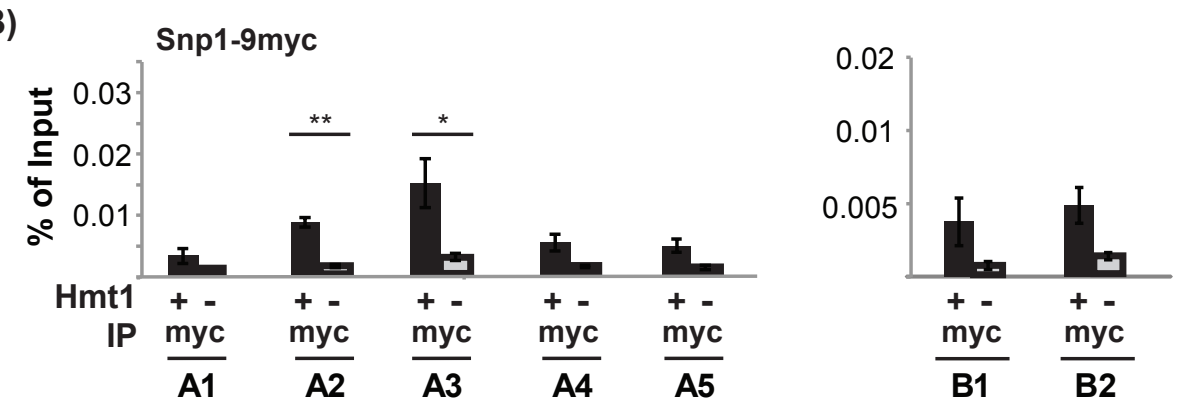

C)
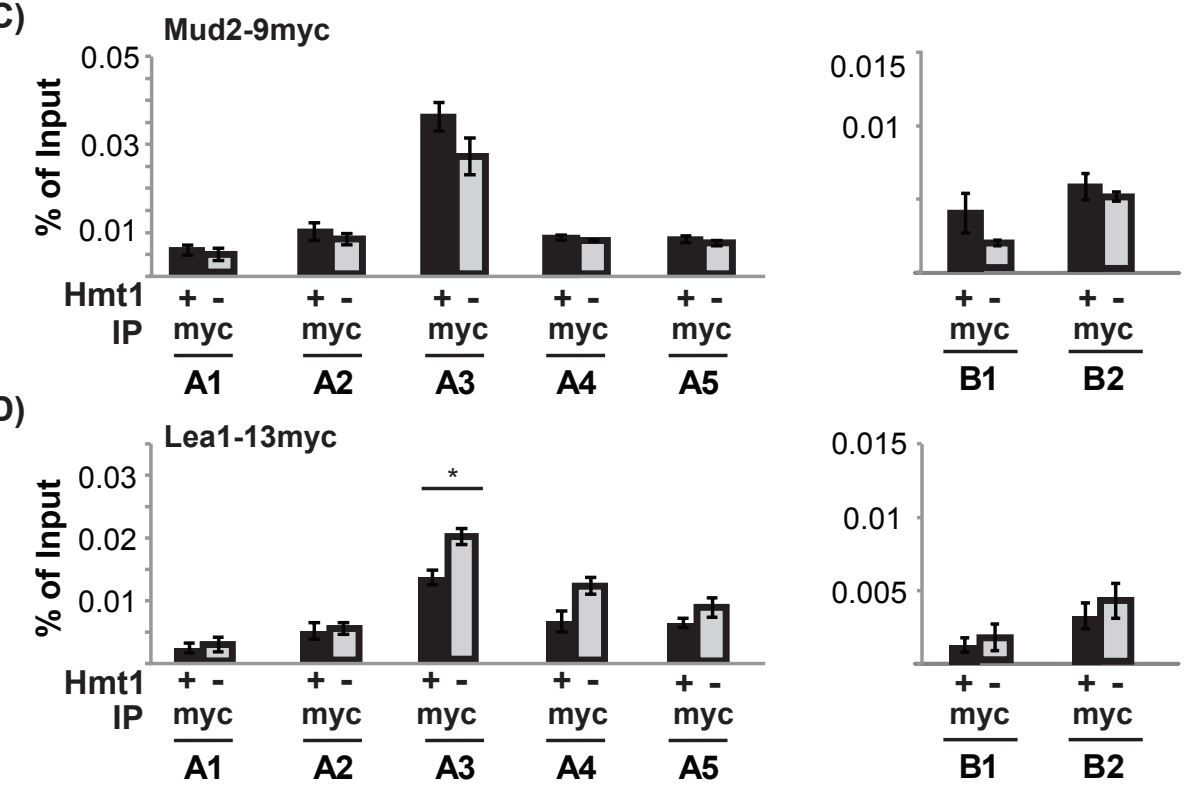

E)
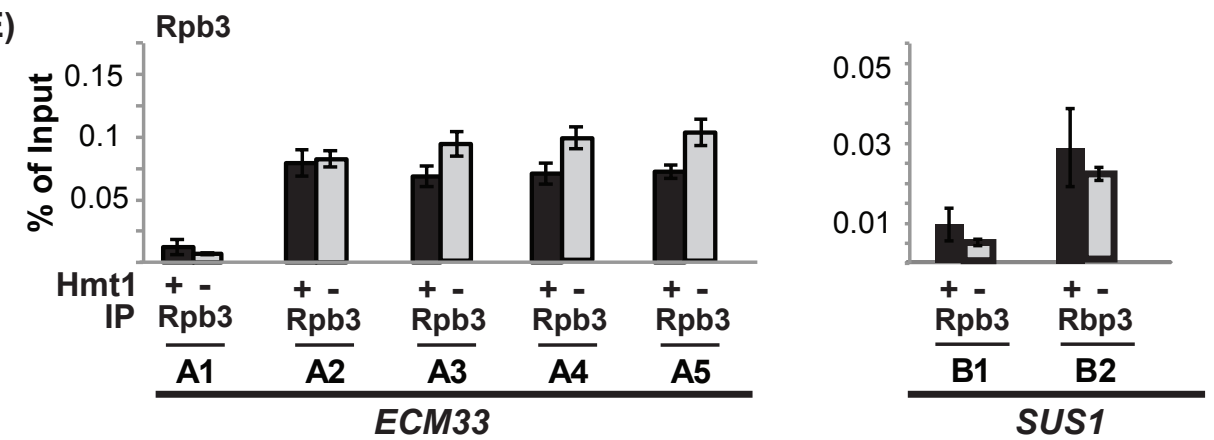

F)

F) Npl3-myc+RNAse
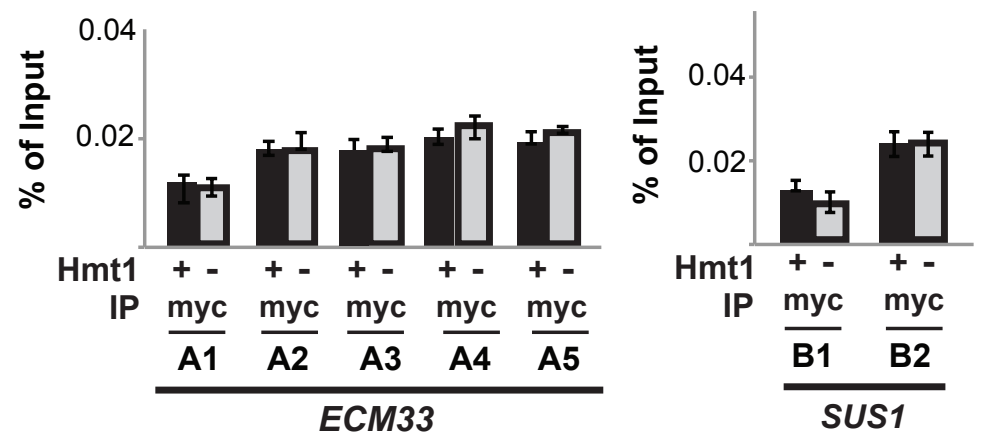

$\frac{\text { IP } \frac{m y c}{\mathrm{~A} 1} \frac{\mathrm{myc}}{\mathrm{A} 2} \frac{\mathrm{myc}}{\mathrm{A} 3} \frac{\mathrm{myc}}{\mathrm{A} 4} \frac{\mathrm{myc}}{\mathrm{A} 5}}{\text { ECM33 }} \quad \frac{\text { IP } \frac{\mathrm{myc}}{\mathrm{B} 1} \frac{\mathrm{myc}}{\mathrm{B} 2}}{\text { SUS1 }}$

G)
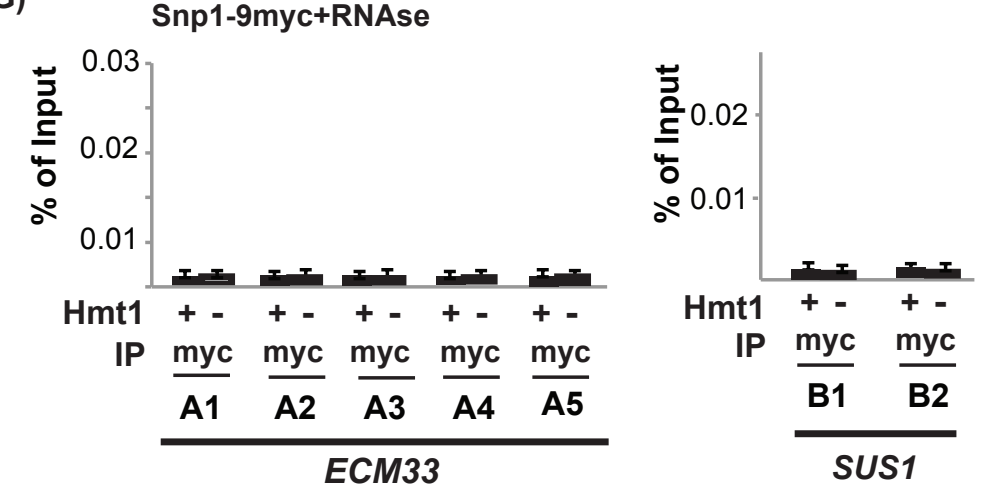
Muddukrishna Figure 3

A)
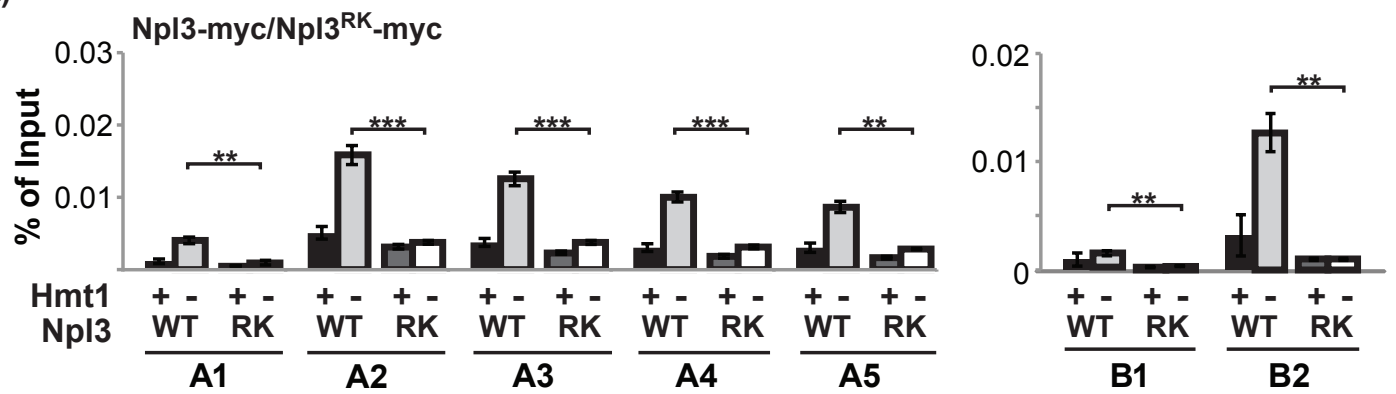

B)
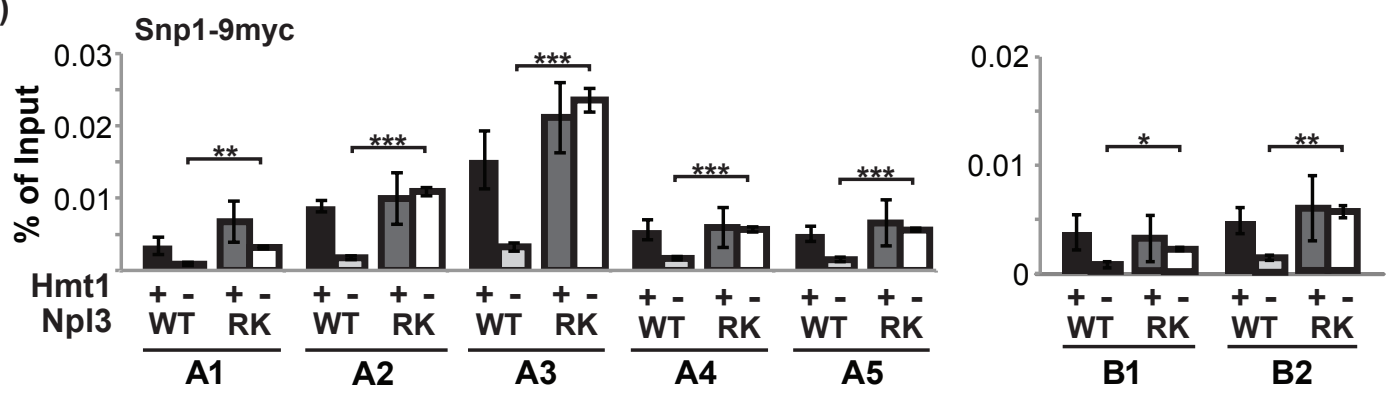

C)
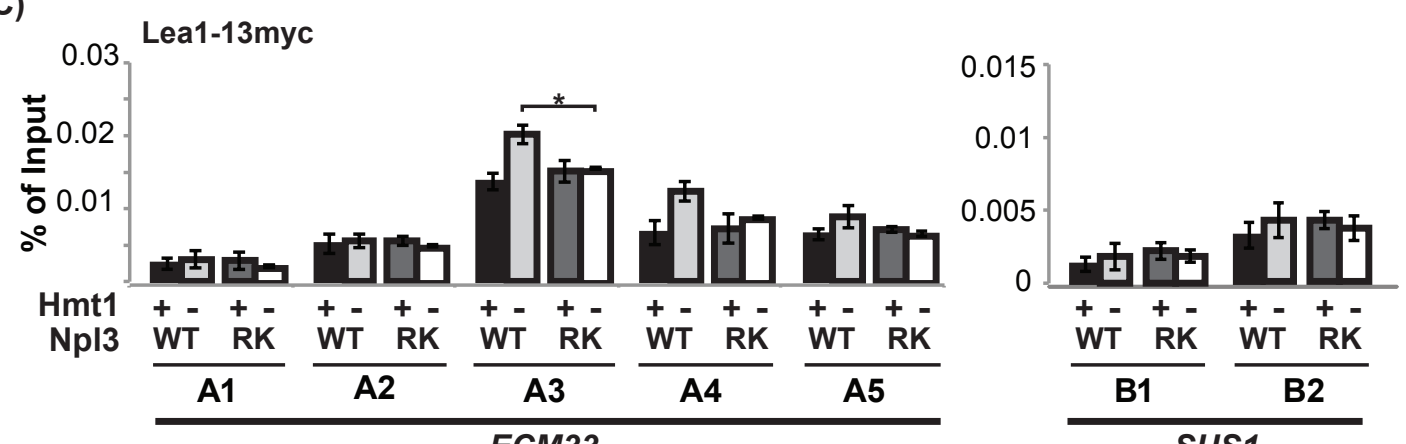
A)

\section{ECM33}

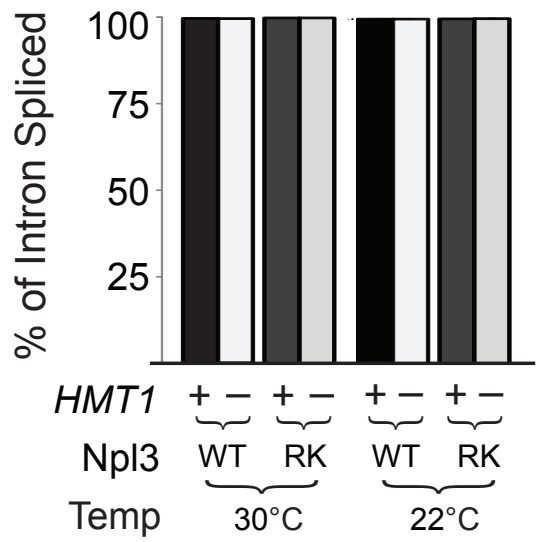

B)

\section{SUS1 (intron 1)}

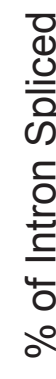

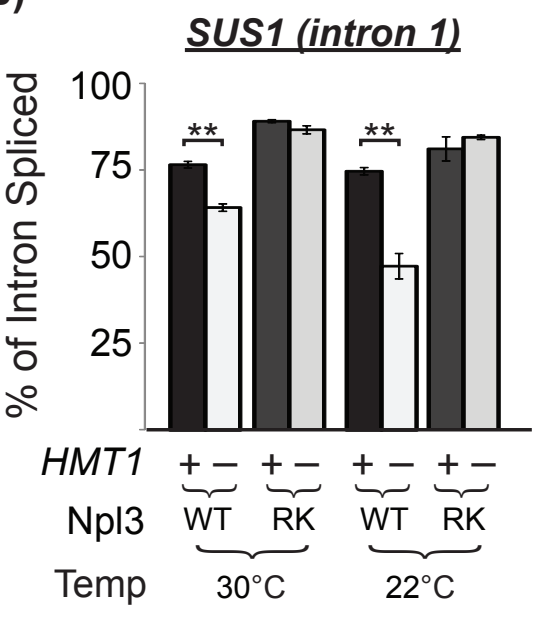

SUS1 (intron 2)

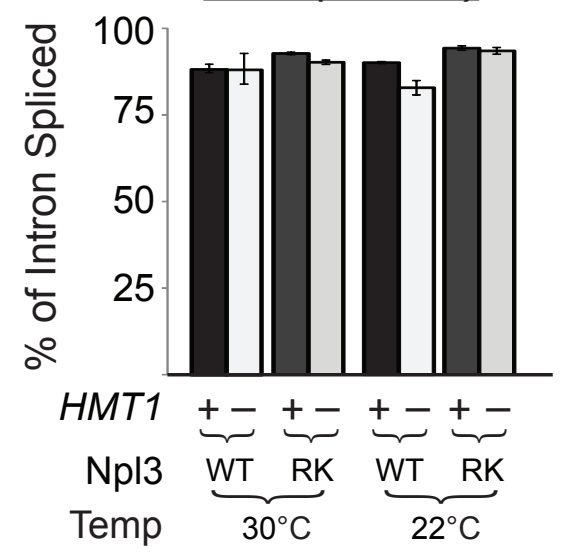


Muddukrishna Figure 5

A)

5' Splice Site
3' Splice Site

B)

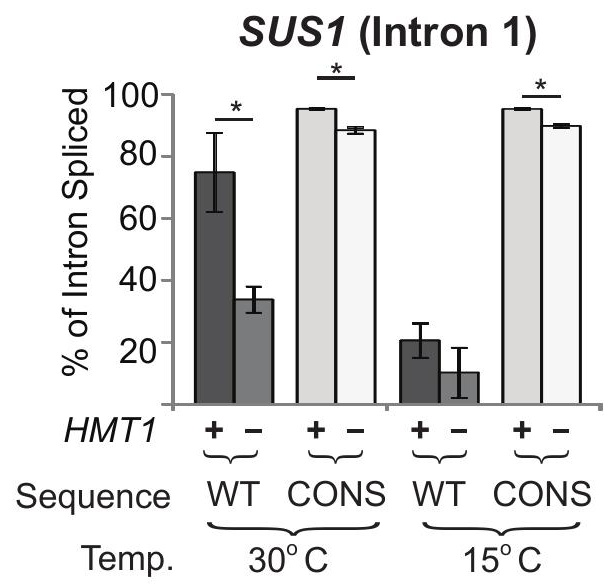

Consensus: GUAUGU

SUS1 (Intron 1): GUAUGA

UACUAAC

UACUGAC

\section{SUS1 (Intron 1)}

Temp. 
A)

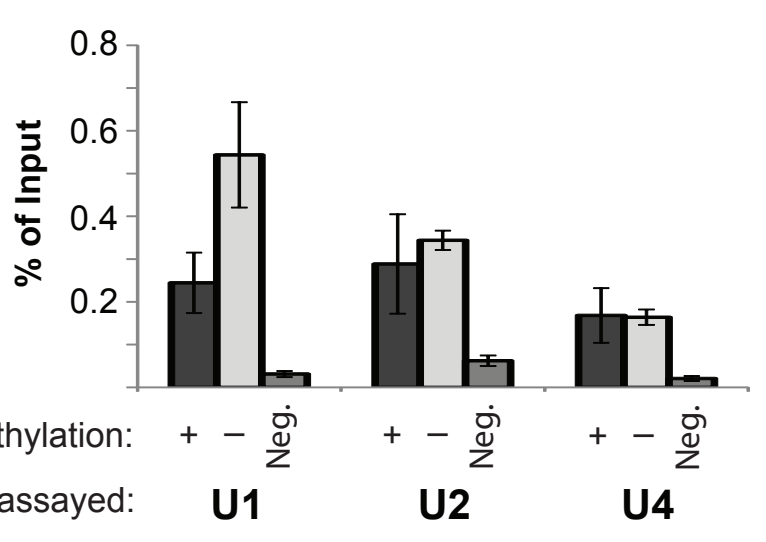

B)

$\begin{array}{lccc}\text { Npl3 Methylation: } & +-\frac{\dot{\Phi}}{2} & +-\frac{\dot{\Phi}}{2} & +-\frac{\dot{\Phi}}{2} \\ \text { U-snRNA assayed: } & \mathrm{U} 1 & \mathrm{U} 2 & \mathrm{U} 4\end{array}$

Npl3 Methylation $+-+_{-}+-\quad+-$

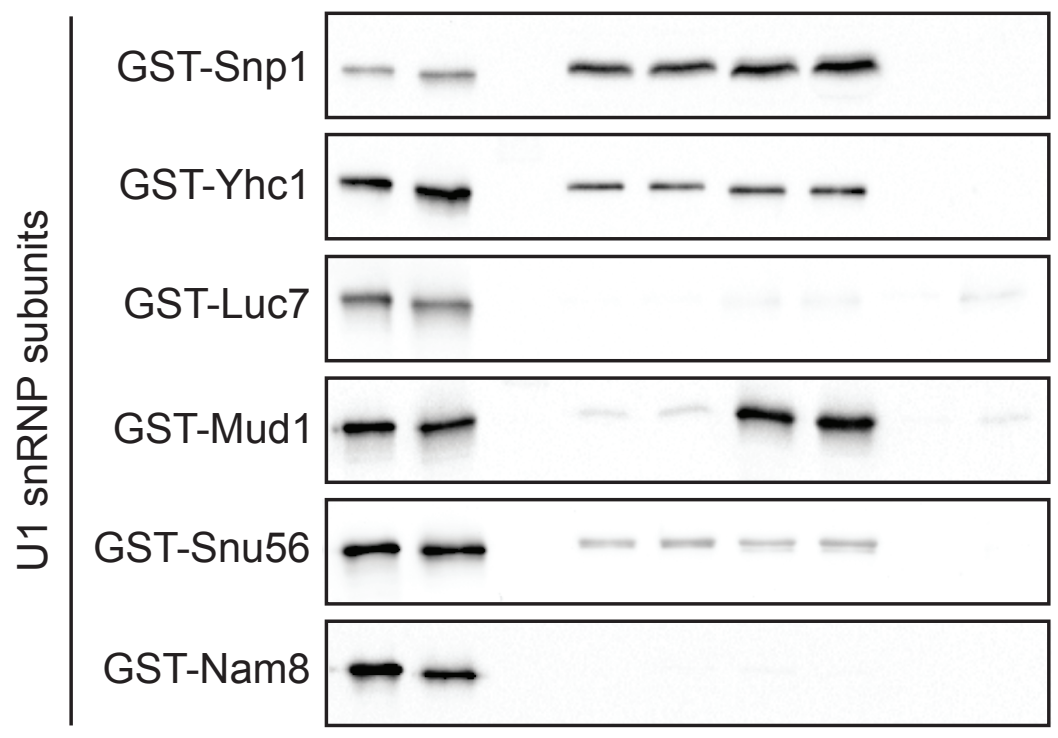

$-0.48$

$-0.38$

N.D.

$-4.75$

$-0.06$

N.D. 